\title{
ESPORTE, SAÚDE E PRÁTICA PEDAGÓGICA EM EDUCAÇÃO FÍSICA
}

\section{John Koumantareas iD ${ }^{1}$ Rogério Cruz de Oliveira iD2}

Resumo: O presente estudo advém de dissertação de mestrado e tem como objetivo compreender como ocorre a relação entre esporte e saúde na prática pedagógica de profissionais de Educação Física no contexto de não formação de atletas. Ou seja, nos espaços e locais onde a competição e consequente profissionalização não constituam seu objetivo final. Assim, vivenciadas para além da dimensão do esporte de rendimento. Para tanto, foi desenvolvida uma pesquisa descritiva de abordagem qualitativa, tendo participado do estudo nove profissionais de Educação Física lotados numa secretaria de esportes de um município localizado na região metropolitana da Baixada Santista - SP. A entrevista semiestruturada foi o instrumento de coleta de dados e versou sobre duas questões: a) a importância do esporte para a vida das pessoas na sua relação com a saúde, e; b) as possibilidades de trabalho com o tema saúde na prática pedagógica em Educação Física. A análise de dados se deu por categorias não-apriorísticas e como resultado, revelou, que, os profissionais de Educação Física compreenderam o esporte como: a) fomentador da saúde; b) estratégia de socialização; e c) sinônimo de saúde; No que tange ao trabalho em saúde na prática pedagógica em Educação Física, constatou-se, que, este ocorre por meio de orientações aos munícipes. Assim, concluiu-se, existir uma visão simplista do binômio esporte-saúde na prática pedagógica em Educação Física.

Palavras-chave: Prática esportiva; Promoção da Saúde; Educação Física; Prática Pedagógica.

\section{SPORT, HEALTH, AND PEDAGOGICAL PRACTICE IN PHYSICAL EDUCATION}

Abstract: The study is a part of master thesis, and their aim was to comprehend the relation between sport and health in the pedagogical practices from Physical Education professionals working in the context of the non-training of athletes. It means, at the locals where the sports' competitions and professionalization do not be its main intention. Thus, the sport apart from high-performance. For that, a descriptive research of qualitative approach was carried out with nine Physical Education professionals working in a Municipal Sports Department of a municipality of Baixada Santista, region of São Paulo state, Brazil. As a data collection instrument, semi-structured interviews were conducted from two

\footnotetext{
${ }^{1}$ Mestre em Ciências pelo Programa de Pós-Graduação Interdisciplinar em Ciências da Saúde na Universidade Federal de São Paulo (UNIFESP), Câmpus Baixada Santista. Educador em Atividades Infantojuvenis - Serviço Social do Comércio (SESC SP). E-mail: koumantareas.john@gmail.com.

${ }^{2}$ Doutor em Educação Física pela Universidade Estadual de Campinas (UNICAMP). Professor do curso de Educação Física e do Programa de Pós-graduação Interdisciplinar em Ciências da Saúde da Universidade Federal de São Paulo (UNIFESP), Câmpus Baixada Santista. E-mail: rogerio.cruz@unifesp.br.
} 
aspects: the significance of sport to people life in relation to health, and; b) the possibilities of the pedagogical practice in relation to sports and health as teaching subject. Data analysis was performed by non-aprioristic categories. As a result, the Physical Education professionals understood the sport as: a) a health promoter; b) strategy of socialization, and; c) synonym for health. Regarding to the possibilities of working with the health theme we found that this occurred through guidance to residents. Thus, we concluded that there is a simplistic view on sport-health binomial in the Physical Education pedagogical practice context.

Keywords: Sport Practice; Health Promotion; Physical Education; Pedagogical Practice.

\section{Introdução}

A estrita relação representada pelo binômio esporte - saúde como estratégia da prática pedagógica em Educação Física norteou o discurso que legitima e embasa suas diversas ações e metodologias, principalmente, naquilo que se refere à importância da prática do esporte no fomento à saúde. Aqui, a ideia que se faz recorrente, sobretudo, via senso comum, é aquela que direta ou indiretamente, protagoniza a prática esportiva na figura do principal agente para o desenvolvimento e manutenção da saúde como um estado, muitas vezes, a ser desfrutado na proporcionalidade de causa e efeito (ALMEIDA; OLIVEIRA; BRACHT, 2016; BRACHT, 2005a, 2005b, 2013; KUNZ, 2007, 2016).

Nesse enredo, acreditamos, que, o esporte como conteúdo da prática pedagógica em Educação Física, integrou-se, popularmente, a termos como atividade física e exercício físico, de forma cartesiana e numa tentativa de um pool para a complementariedade dos mesmos. A preocupação com o bom funcionamento do corpo, a fuga do chamado padrão de morbimortalidade e a saúde a qualquer custo passam a ser os objetivos de qualquer indivíduo praticante de determinada modalidade esportiva. Assim, enaltecendo, aspectos pragmáticos relacionados à sua apropriação, tais quais: a culpabilização individual, bem como a ocultação, muitas vezes inconsciente, do sujeito que está no foco da prática esportiva e o reforço de padrões de comportamento única e exclusivamente pautados pela estética corporal (CARVALHO, 2001; COSTA, GARCIA; NAHAS, 2012; CZERESNIA, 2003; FERREIRA, CASTIEL; CARDOSO, 2011; LOVISOLO, 2006; PALMA, ESTEVÃO; BAGRICHEVSKY, 2003).

As inter-relações supracitadas no sentido da prática esportiva com vista à saúde, além de reduzir sua compreensão por meio de uma forma simplista, em grande parte, corroboram com a ideia da prática com fim nela mesma. Desse modo, sem promover estratégias facilitadoras para sua devida apropriação e o desenvolvimento do senso crítico pelos praticantes (CARVALHO, 2001; KUNZ, 2007, 2016). 
O corpo e consequentemente o movimento humano, tidos a partir da simplicidade na sua compreensão, em muitos casos, trazem no seu bojo o esporte de rendimento como principal possibilidade e modelo a ser seguido, principalmente, pelo viés da aptidão física, e como consequência, supervalorizando o modelo biomédico para o conceito de saúde (BRACHT, 2005a, 2005b, 2013; CASTELLANI FILHO, 2015; KUNZ, 2007, 2016).

A nosso ver, a problemática desenhada, por ora, é perpetuada na prática pedagógica em Educação Física por meio do binômio esporte-saúde, devido a dois principais aspectos. No primeiro deles, por conta da sua fundamentação histórica e formativa no paradigma biomédico, conhecidamente originário da área da medicina social e dos estudos epidemiológicos, bem como pela adoção do conceito estrito na relação saúde-doença. Já no segundo, devido ao discurso fundamentado sob a égide da promoção da saúde, bem como do seu fomento, independentemente das estratégias, dos sentidos e significados que são incorporados e, que, emergem deste enredo (KNUTH; LOCH, 2014; OLIVEIRA, MARTINS; BRACHT, 2015; PALMA, 2020).

Nessa esteira, consideramos interessante, o processo de ampliação do debate conceitual acerca desse conteúdo na prática pedagógica em Educação Física. Para tanto, o presente texto, compreende o conceito de esporte, a partir da teoria do se-movimentar, proposta por Elenor Kunz (2016, p.68), ao nos propor um sentido amplo para o seu entendimento e nos convidar à seguinte reflexão:

\begin{abstract}
O que seria então um conceito "amplo" de esporte? Será que andar de bicicleta, caminhar, fazer ginástica, dançar, as brincadeiras e os jogos infantis etc., não podem, também, ser entendidos como esportes? Em caso afirmativo, temos aí um conceito "amplo" de esporte. Quantas vezes já não ouvimos de pessoas que dizem que o "seu esporte" é ir de bicicleta ao trabalho, dançar nos fins de semana ou caminhar na praia? No cotidiano, estes "esportes" existem, e qual é a preocupação da Educação Física sobre este tipo de esporte?
\end{abstract}

Em nosso entendimento, a provocação supracitada nos atenta para o trato com o conceito de esporte numa proposta de ressignificação, buscando o rompimento com a ideia estereotipada acerca da prática esportiva altamente institucionalizada e com fim nela mesmo. Assim, a compreensão acerca daquele que não se movimenta, consequentemente integrando as estatísticas epidemiológicas no campo do sedentarismo, além de ser classificado como principal culpado na relação entre saúde e o processo de adoecimento - por meio do paradigma estrito - e, que, de certo modo, não exerça sua plenitude, naquilo que se refere à qualidade de vida e ao bem-estar como indicadores quantitativos para tal demanda, passa a protagonizar a relação entre prática esportiva e saúde. Para nós, tamanho entendimento se justifica a partir do pensamento de Devide (2002, p. 77), ao nos afirmar que as relações entre atividade física, exercício físico e qualidade de vida são "[...] empíricas e testemunhadas por nós no [sic] quotidiano".

Ora, se a relação entre a prática do esporte, bem como das atividades e exercícios físicos como possibilidade de experimentação da qualidade de vida e do bem-estar estão para as experiências prévias, bem como para as 
expectativas que os indivíduos trazem consigo, o entendimento de tal fenômeno deve ocorrer num diálogo com sua perspectiva cultural, de modo a ampliar o debate e o seu processo de ressignificação. Tal constatação tem como base um curioso paradoxo pós-moderno: se por um lado temos acesso a uma enxurrada de informações disponíveis acerca do tema, aquilo que se evidencia, são os altos níveis de sedentarismo que vão ao encontro dos números insatisfatórios de prática esportiva na sociedade e desse modo, relatados nos documentos oficiais divulgados pelo Ministério do Esporte $^{3}$ (BRASIL, 2015; 2016).

Nesse sentido, aquilo que pode ser entendido numa relação de causalidade entre a prática esportiva e o discurso da saúde como qualidade de vida e bemestar, são desconstruídos ainda em Devide (2002, p.77-78), ao vermos que:

[...] a qualidade de vida emerge sob uma subjetividade que torna difícil a conceituação estrita do termo, que se refere, sobretudo, à história pessoal de cada um de nós, [...] qualidade de vida tem dinâmica própria, por estar relacionada à cultura local, fazendo com que se devam respeitar as singularidades de cada comunidade e indivíduo em si, evitando padrões conceituais. [...] a busca por uma qualidade de vida tem sido uma constante nas sociedades. Isso tem gerado tentativas de se estabelecer valores para o nível de qualidade de vida, a partir de indicadores econômicos, taxas de natalidade, mortalidade infantil, esperança de vida, alfabetização, consumo alimentar, prática de atividade física, entre outros aspectos que traduzem sua complexidade, enredada que está em questões de ordem social, como meio-ambiente, segurança e promoção da saúde.

No geral, pode-se entender que do mesmo modo que o ser humano possui suas individualidades biológicas e culturais, a compreensão sobre esporte e saúde como conteúdo da prática pedagógica em Educação Física, deveria guiarse pela mesma concepção, principalmente quando propõe a qualidade de vida no foco do discurso que é propagado. Assim, a ideia acerca da qualidade de vida e do bem-estar está para além de uma simplista, devendo ocorrer por meio da relativização inerente a cada um dos indivíduos.

Nessa esteira, no que se refere à ideia de saúde, circunscrita à prática esportiva, compreendemos, que, a mesma, deva seguir também no sentido de sua ampliação. Assim, é que para fins deste estudo, a saúde será assumida de acordo com Minayo (2014) e em conformidade com a VIII Conferência Nacional de Saúde, realizada no Brasil em 1986, que, nos traz à luz, o seu entendimento como um direito de todos os cidadãos, sendo a

[...] resultante de alimentação, habitação, educação, renda, meio ambiente, trabalho, transporte, emprego, lazer, liberdade, acesso e posse da terra e acesso a serviços de saúde. E, assim, antes de tudo, o resultado das formas de organização social da produção, as quais podem gerar grandes desigualdades nos níveis de vida. Direito à saúde significa a garantia, pelo Estado, de condições dignas de vida e de acesso universal

\footnotetext{
${ }^{3}$ Após as eleições majoritárias de 2018, o então Ministério do Esporte assumiu o caráter de Secretaria de Governo subordinada ao Ministério da Cidadania.
} 
e igualitário às ações e serviços de promoção, proteção e recuperação de saúde.

Isso posto, a ideia entre a prática pedagógica em Educação Física por meio do esporte, do exercício e da atividade física, tão logo, pelo binômio esporte-saúde como preponderantes à relação entre qualidade de vida e bemestar, deve romper com os paradigmas estritos para sua compreensão. Logo, o que se defende, é a proposição deste objetivo por meio do refinamento acerca do trato do processo de educação para a saúde de forma permanente, crítica e autônoma. Nessa ótica, concordamos e utilizamo-nos de Bracht (2005a, p.42), quando o autor nos mostra que para a elaboração de uma efetiva prática e teoria pedagógica em Educação Física, devem-se responder duas questões básicas: "[...] o porquê (sentido) e o como (instrumental)".

Nesse sentido, e em consonância com os preceitos apresentados como fundamentais na concepção ampliada dos conceitos de esporte e saúde na sua inter-relação com a prática pedagógica em Educação Física, o objetivo deste estudo é: compreender como ocorre a relação entre esporte e saúde na prática pedagógica de profissionais de Educação Física no contexto de não formação de atletas. Ou seja, nos espaços e locais onde a competição e consequente profissionalização não constituam seu objetivo final. Assim, vivenciadas para além da dimensão do esporte de rendimento.

\section{Metodologia}

O estudo que se desenha por hora provém de investigação acerca do binômio esporte-saúde, apresentada e defendida em dissertação de mestrado no ano de 2017. O estudo foi aprovado pelo Comitê de Ética em Pesquisa da Universidade Federal de São Paulo - UNIFESP de acordo com o parecer no $1017 / 2016$. No seu desenvolvimento, foi realizada uma pesquisa descritiva de abordagem qualitativa, a qual não permite visões isoladas, parceladas e estanques, de acordo com Triviños (2009). Parafraseando Thomas, Nelson e Silverman (2012, p.293), propõe-se um: "[...] estudo do status". No caso, o status da prática pedagógica dos profissionais de Educação Física.

A pesquisa se desenvolveu num município localizado na região metropolitana da Baixada Santista/SP. A escolha deste município se deu por conta da organização e oferta de equipamentos - ginásios, piscinas, praças e quadras poliesportivas, bem como eventos e as diversas modalidades esportivas gratuitas para a população, figurando como fatores preponderantes ao título de cidade mais esportiva do Brasil, conforme informações constantes no site oficial do município, na época de realização do estudo. Foram selecionados dois equipamentos esportivos localizados respectivamente na zona da orla e na zona noroeste da cidade conforme sua divisão geográfica.

Nos critérios de inclusão do estudo, foram considerados: a) os voluntários/as titulares de cargo efetivo no referido município há pelo menos 1 (um) ano, b) graduados/as em Educação Física e com atuação em projetos públicos esportivos há pelo menos 2 (dois) anos. Aqui, salienta-se que na concepção destes critérios, considerou-se a experiência profissional dos mesmos. 
Nos critérios de não inclusão, foram considerados os voluntários/as que não responderam alguma das questões elencadas, desse modo, comprometendo o processo de análise dos dados. Para a coleta dos mesmos, foram aplicadas entrevistas semiestruturadas, compreendidas no horizonte da chamada: "[...] conversa com finalidade" de acordo com os pressupostos de Minayo (2014).

A escolha pelos dois equipamentos em questão se deu por conta da sua estrutura física e quantidade de modalidades esportivas ofertadas. Participaram do estudo nove profissionais ${ }^{4}$ de Educação Física de ambos os sexos e em qualquer faixa de idade, sendo três profissionais do sexo feminino e seis profissionais do sexo masculino. No tocante à sua lotação, foram entrevistados cinco profissionais no centro esportivo da zona da orla (ZO): dois do sexo feminino e três do sexo masculino. No centro esportivo localizado na zona noroeste $(\mathrm{ZN})$ da cidade, foram entrevistados quatro profissionais, sendo: um do sexo feminino e três do sexo masculino, conforme o quadro a seguir:

\section{Quadro 1 - Caracterização dos/as profissionais entrevistados/as.}

\begin{tabular}{|c|c|c|c|c|c|c|}
\hline NOME ${ }^{5}$ & $\mathbf{I}$ & POSGRAD & LA & TA $^{6}$ & MOD & CARGO \\
\hline Margarida & 63 & $\begin{array}{c}\text { Especialização } \\
\text { em Educação } \\
\text { Física escolar, } \\
\text { Jogos } \\
\text { Cooperativos e } \\
\text { Gestão Escolar }\end{array}$ & $\mathrm{ZO}$ & 41 & Basquetebol & PEF \\
\hline Maria & 43 & $\begin{array}{c}\text { Especialização } \\
\text { em Musculação } \\
\text { e Treinamento } \\
\text { de Força }\end{array}$ & $\mathrm{ZO}$ & 10 & $\begin{array}{c}\text { Ginástica } \\
\text { Localizada, } \\
\text { Alongamento e } \\
\text { Caminhada }\end{array}$ & PEF \\
\hline José & 39 & $\begin{array}{c}\text { Especialização } \\
\text { em Atividade } \\
\text { Física } \\
\text { adaptada e } \\
\text { saúde }\end{array}$ & $\mathrm{ZO}$ & 8 & $\begin{array}{l}\text { Basquetebol } \\
\text { Adaptado, } \\
\text { Musculação e } \\
\text { Hidroginástica }\end{array}$ & PEF \\
\hline João & 34 & $\begin{array}{c}\text { Especialização } \\
\text { em Fisiologia } \\
\text { do Exercício }\end{array}$ & $\mathrm{ZO}$ & 9 & Musculação & PEF \\
\hline Rodrigo & 38 & $\begin{array}{l}\text { Especialização } \\
\text { em } \\
\text { Metodologia do } \\
\text { Treinamento } \\
\text { Personalizado }\end{array}$ & $\mathrm{ZO}$ & 10 & Musculação & PEF \\
\hline Fernanda & 40 & $\begin{array}{l}\text { Especialização } \\
\text { em Atividade }\end{array}$ & $\mathrm{ZN}$ & 8 & $\begin{array}{c}\text { Natação, } \\
\text { Hidroginástica, }\end{array}$ & PEF \\
\hline
\end{tabular}

${ }^{4} \mathrm{Na}$ época da coleta de dados, existiam 98 profissionais de Educação Física cadastrados na referida Secretaria Municipal de Esportes, conforme informações constantes no portal da transparência dos recursos públicos do município.

${ }^{5}$ Para preservar a identidade dos voluntários/as foram usados pseudônimos.

6 O tempo de atuação na Secretaria Municipal de Esportes do referido município corresponde até a data de realização das entrevistas: agosto a outubro de 2016. 


\begin{tabular}{|c|c|c|c|c|c|c|}
\hline & & $\begin{array}{c}\text { Física } \\
\text { adaptada e } \\
\text { saúde }\end{array}$ & & & $\begin{array}{c}\text { Ginástica } \\
\text { Localizada e } \\
\text { Alongamento }\end{array}$ & \\
\hline Joaquim & 29 & $\begin{array}{c}\text { Especialização } \\
\text { em } \\
\text { Treinamento } \\
\text { Desportivo }\end{array}$ & ZN & 4 & $\begin{array}{c}\text { Natação, } \\
\text { Hidroginástica } \\
\text { e Polo aquático. }\end{array}$ & TD \\
\hline Jorge & 34 & $\begin{array}{c}\text { Especialização } \\
\text { em } \\
\text { Aprendizagem } \\
\text { Motora e } \\
\text { Educação } \\
\text { Física escolar }\end{array}$ & ZN & 4 & $\begin{array}{l}\text { Ginástica } \\
\text { Artística }\end{array}$ & TD \\
\hline Daniel & 33 & $\begin{array}{l}\text { Mestrado em } \\
\text { Educação } \\
\text { Física }\end{array}$ & ZN & 4 anos & $\begin{array}{l}\text { Ginástica } \\
\text { Artística }\end{array}$ & $\mathrm{TD}$ \\
\hline
\end{tabular}

Fonte: própria dos autores.

I: idade (em anos); POSGRAD: Pós-graduação cursada; LA: local de atuação; TA: tempo de atuação (em anos); MOD: modalidade ministrada; PEF: Professor (a) de Educação Física; TD: Técnico-desportivo (a).

Todas as entrevistas e o recrutamento dos voluntários/as ocorreram no seu próprio local de lotação e atuação. Ou seja, nos dois equipamentos esportivos elencados no presente estudo, mediante datas e horários previamente agendados. Ainda no que se refere a esta etapa, a mesma se deu de duas formas: a) visita prévia e conversa com os profissionais de Educação Física para apresentação e convite para participarem do estudo; e b) confirmação de interesse em participação via contato por e-mail e posterior agendamento da entrevista. Nesse enredo, os/as profissionais responderam a duas questões inerentes ao escopo da pesquisa, como segue: a) Qual a importância do esporte para a vida das pessoas na sua relação para com a saúde? e; b) A partir da sua prática pedagógica em Educação Física e esportes, em quais momentos você enxerga as possibilidades de trabalho com o tema saúde? Todas as entrevistas foram gravadas com o consentimento dos/as voluntários/as e, posteriormente, transcritas para um arquivo eletrônico para análise.

A análise dos dados se deu por meio de categorias não-apriorísticas, as quais surgiram por meio do processo incessante na leitura e releitura das entrevistas transcritas. As categorias foram interpretadas à luz de Campos (2004), seja por frequenciamento (respostas comuns a dois/duas ou mais voluntários/as) ou relevância implícita (resposta de um/a único voluntário/as, mas que guarda coerência com o objeto de estudo). Importante ressaltar ainda que uma mesma resposta pode ser interpretada em duas ou mais categorias.

Assim, quando perguntados sobre a importância do esporte para a vida das pessoas em sua relação com a saúde, o conjunto de respostas nos permitiu identificar três categorias de análise:

- Esporte como fomentador da saúde: Margarida, Maria, José, João, Jorge e Daniel; 
- Esporte e saúde como estratégia de socialização: Margarida, João, Rodrigo e Fernanda;

- Esporte como sinônimo de saúde: Joaquim.

$\bullet$

Já no que se refere à prática pedagógica em EF e o trabalho com o tema da saúde, todas as respostas convergiram para uma única categoria:

- Trabalho em saúde por meio da orientação.

\section{Resultados e discussões}

3.1 Esporte $\mathrm{x}$ saúde: importância na vida das pessoas

Na categoria Esporte como fomentador da saúde, o papel do esporte se deu como estratégia fundamental com base nos recortes atrelados à aprendizagem dos gestos esportivos e a consequente internalização dos mesmos. Principalmente, no que se refere às suas inter-relações com o campo da saúde por meio de sua concepção estrita, conforme demonstrado nos seguintes relatos:

\footnotetext{
"[...] ele [o esporte] ajuda na saúde das pessoas, é fundamental!" Margarida. "[...] muito importante! É primordial, fundamental, é o que vai fazer com que essa pessoa promova saúde nela" - Maria. "[...] o esporte nesse quesito tem que ser visto como algo fundamental; fundamental na nossa sociedade" - José. "[...] é um assunto bem denso, [...] com a diminuição das atividades físicas das pessoas, eu acho que... [...] o esporte acaba preenchendo esta lacuna, né?" - João. "A relação entre esporte e saúde se dá sim, ela se dá! Principalmente na prática, quando visamos a preparação dos alunos" - Jorge. "[...] na minha opinião é uma condição que o atleta vai ter para beneficiar-se ao longo da vida" - Daniel.
}

Nitidamente influenciados pela ideia de permanência na prática esportiva ao longo da vida, a fundamentalidade do esporte no fomento à saúde perpassa diretamente pelo viés da aptidão física, no qual as questões inerentes à prática esportiva e à saúde como consequência direta estejam propensas ao diálogo numa perspectiva utilitarista e pragmática (CARVALHO, 2001; PAES, GALATTI; SEOANE, 2012; KUNZ, 2007, 2016).

$\mathrm{Na}$ ideia central das respostas obtidas, percebeu-se a comparação entre os indivíduos que praticam ou não alguma modalidade esportiva. Com isso, ganhou ênfase a concepção de que, o quão cedo se der o contato com esse universo, por consequência, maior será a aderência das pessoas no tocante à prática regular do esporte com vista à saúde. Todavia, ainda neste contexto, para que se alcance uma efetiva preocupação com o tema, se faz necessária uma concepção ampla para o trato do esporte. Ou seja, assim como demonstrado por Kunz (2016), entendê-lo [o esporte] para além da prática das modalidades esportivas altamente institucionalizadas, com especial atenção aos processos de ensino e aprendizagem esportivas, compreendendo que, para que se tenha uma ação propositiva no tocante à saúde das pessoas, tão logo a prática esportiva seja fundamental, também seja necessário ultrapassar a fronteira do implícito nessa condição (CARVALHO, 2001; PAES; BALBINO, 2011; PAES, GALATTI; SEOANE, 2012). 
Para tanto, se de um lado, tem-se reforçada a crença de que o esporte e sua prática promovam saúde, cabe o questionamento acerca do como se fazer isso na prática, sobretudo, dada a concepção de que ao se ensinar o esporte numa perspectiva qualitativa, o que se deve ter como premissa, é a preocupação em ensinar muito mais do que apenas a correta execução de gestos motores no seu principal exemplo (KUNZ, 2016; PAES; BALBINO, 2011; SCAGLIA; REVERDITO, 2009).

Nessa esteira, a relação causal do fomento à saúde por meio do esporte deixa de ser o foco do trabalho, corroborando com a compreensão acerca das estratégias e metodologias dialógicas na perspectiva sociocultural dos praticantes. Em suma, o sujeito na prática esportiva é o protagonista. Cabe, nesse sentido, a reflexão na proposição de múltiplos modelos na prática esportiva com vista à saúde como uma proposta permanente de educação em saúde. Inferir nas diferentes possibilidades existentes nesse processo traduz a riqueza e complexidade no trabalho com o tema. Bracht (2013), ao refletir sobre a saúde na Educação Física escolar, compreende que o paradigma de uma educação para a saúde pautada no cuidado de si guarda relevância à medida em que favorece a autonomia e o empoderamento dos/a alunos/as frente às demandas do faça atividade física e seja saudável (viés fomentador de saúde). Nesse sentido, o autor defende que a abordagem da saúde na Educação Física escolar deva ser uma questão pedagógica e não fisiológica. Embora Bracht tenha se pronunciado no contexto do sistema educacional, compreendemos que a reflexão pode ser aplicada ao cenário do sistema esportivo de não formação de atletas por dois motivos: o esporte é educacional onde for encenado (KUNZ, 2016), e; o protagonismo do/a aluno/a nos processos educativos guarda estreita relação com a autonomia e o empoderamento, que, ao se tratar de saúde, o cuidado de si é ator principal.

Para Pich (2016), cuidar de si possibilita às pessoas dotarem-se de conhecimentos que as permitem serem soberanas de si mesmo, ou melhor, governarem-se. Isso significa tomar as rédeas das próprias decisões para além dos ditames contemporâneos do movimente-se a qualquer custo e de qualquer forma.

No tocante à segunda categoria, denominada: Esporte e saúde como estratégia de socialização, a mesma se deu na perspectiva da convivência das pessoas em grandes grupos ao longo da prática esportiva, processo no qual, o trato com a saúde figura na possibilidade de vivência de forma coletiva e até certo ponto, automática, como pertencente ao próprio processo de formação da sociedade pós-moderna. Tal categoria fundamentou-se com base nos seguintes recortes:

"[...] sem contar no convívio social com outras pessoas, no aspecto da sociabilização promovida por meio do esporte de participação... [...] Da atividade física" - Margarida. "[...] tem a questão do grupo também, né? Eu acho que o esporte entra nessa parte aí.... [...] De convivência social, de você se unir a outras pessoas, tanto individualmente como competir" - João. "[...] quando você pratica o esporte numa concepção de jogo, a relação entre você e o seu grupo, bem como com os expectadores e demais competidores já melhora, numa concepção de saúde em grupo; convivência; socialização" - Rodrigo. "[...] nas aulas de ginástica 
localizada, [...] seja comigo ou com as outras, elas [alunas] acabam trabalhando essa prática social [a saúde]; esse lado social" - Fernanda.

O trabalho em saúde nos grandes grupos foi relatado como uma prática social e inerente ao cotidiano dos/as voluntários/as, compreendendo saúde numa perspectiva coletiva. A ideia de construção de redes de convívio por meio da vivência no esporte é reforçada. Nesse contexto, o sujeito que pratica esporte passa a ser o foco do trabalho. Ainda que o processo de facilitação acerca do diálogo para com a prática esportiva em grupos aconteça, existe o reconhecimento que esse trabalho se dê de forma indireta, porém, ligada ao processo de ensino e vivência esportivo. Entende-se aqui que, num ambiente propício para o convívio coletivo, também se pode propiciar sessões de bemestar e alívio no que se refere às diversas questões pessoais e coletivas acerca da prática esportiva. No estudo de Bergamo e Silva (2020), que analisaram os significados das atividades esportivas e de lazer para frequentadores (as) de um programa esportivo na cidade de Indaiatuba-SP, a socialização e a busca de amizades apareceram como fatores privilegiados das análises. Já no estudo de Santos, Fouraux e Oliveira (2017), a socialização é percebida como um dos pontos relevantes na vida de uma atleta de bocha paralímpica.

A concepção de socialização em saúde por meio da prática esportiva que se desenha, aqui, tem como base a dimensão do esporte de participação como proposto em Tubino $(2006 ; 2010)$. Desse modo, priorizando a vivência esportiva sem fins na competição altamente institucionalizada, passíveis ainda de sua justificativa em Kunz (2016). Logo, a ideia de que a prática esportiva fomente a experiência em saúde por meio da massificação do fenômeno esportivo é relativizada. A compreensão acerca do caráter motivacional na prática esportiva de forma regular serve como mote. Nesse aspecto, as pessoas contagiam-se positivamente pela dinâmica das aulas e demais vivências por meio do esporte.

$\mathrm{Na}$ concepção dos/as voluntários/as, o esporte e a saúde, além de estarem diretamente ligados no papel de facilitadores do trabalho permanente em saúde, caracterizam na sua prática, importante ferramenta naquilo que se refere ao movimento humano numa melhor condição de saúde, mesmo que por vezes reforcem características e valores do esporte de rendimento como principal possibilidade. Aliás, recorrente no processo de apropriação da prática esportiva (DAOLIO; VELOZO, 2008).

Nesse sentido, acerca do imediatismo nas relações entre prática esportiva e saúde, concordamos com Marinho (2010, p.18) ao dizer que:

Nem sequer conseguimos entender nosso próprio corpo, por intermédio do qual se manifestam as práticas esportivas. Em uma perspectiva materialista vulgar, somos aquilo que comemos. Por mais simplificada que seja esta imagem do ser humano, ainda encontramos seus defensores [...] em uma perspectiva fenomenológica, colocamos nosso corpo "entre parênteses", isolando-o de todo o processo histórico que o produz. O homem, individualmente, é o responsável por tudo que lhe acontece, deixando de lado as condições materiais de sua existência.

Embora o autor critique de forma rígida a problemática proposta, o posicionamento favorável que temos nesse instante, sobretudo, pelo papel do 
corpo na relação com uma prática esportiva imediatista e utilitarista, na qual, desconsideram-se a historicidade dos processos de construção e identidade do mesmo por meio do esporte, além do emprego do conceito de saúde fundamentado no modelo biomédico, concordamos, que, nesse sentido, o que ocorra, é a redução desta problemática ao viés pura e estritamente pragmático no processo de saúde e adoecimento. Aqui, vale problematizar tal entendimento, inclusive, por meio da individualidade dos sujeitos, uma vez que a Educação Física no seu projeto de significação social, em diversos momentos, deixou para um segundo plano a compreensão do próprio ser humano em sua totalidade (CARVALHO, 2001; DAOLIO, 2004, 2005, 2007).

No que se refere à terceira categoria, aqui, intitulada: esporte como sinônimo de saúde, a mesma se deu com base no seguinte recorte:

"[...] eu acredito que a saúde no esporte vai até um determinado ponto. A partir do alto rendimento, quando entramos no treinamento de alto rendimento, o esporte deixa de ser saúde; ocorrem lesões" - Joaquim.

Ou seja, para Joaquim, esporte e saúde são indissociáveis em todos os contextos, com exceção do esporte profissional, cenário no qual a saúde física (lesões) é transgredida. Nesse ponto, é pertinente concordarmos com o seu discurso, já, que, o mesmo, corrobora com a ideia acerca do rendimento físico a qualquer custo, no qual o corpo é levado a situações extremas de estímulos e consequentemente situações de reprodução das capacidades e habilidades biomotoras plausíveis às mais diversas formas de expressão do fenômeno esportivo, condição esta, que, ganha força nas palavras de Kunz (2016, p.33):

Os motivos desse fenômeno não estão no desenvolvimento do esporte em si, mas no próprio desenvolvimento das sociedades atuais, em que o rendimento se configura no princípio máximo de todas as ações. Por isso impõe exigências cada vez mais altas, sem jamais retroceder. Se, por exemplo, um atleta para ultrapassar um recorde mundial precisa se submeter a um tratamento inumano, isso pouco importa desde que o resultado seja alcançado.

Nessa esteira, a ideia do autor suscita uma discussão aprofundada acerca do problema para além de questões como competição exacerbada, sucesso esportivo e vitória a qualquer custo, naquilo que Bracht (2005a) elencou como alguns dos princípios da chamada instituição esporte, presente na construção dos valores e da identidade das pessoas no que se refere à prática esportiva.

$\mathrm{Na}$ vida em sociedade pós-moderna, cabe a reflexão de que o esporte exerça uma grande parcela no processo de apropriação do conceito de saúde. Entretanto, a principal questão que se levanta nesse ponto, é aquela que compreende que o esporte e sua prática devem compor uma complexa rede de fatores no processo de significação qualitativa dessa relação.

Nesse sentido, é pertinente citar trabalhos que se debruçaram sobre a pedagogia do esporte para abordar o ensino de lutas (GOMES et al., 2010), natação (LOTTI; OLIVEIRA, 2016) e futebol (SILVA, 2020), que, embora produzidos em épocas diferentes, são consensuais sobre processos educativos mais abertos à experiência dos/as alunos/as. Em nosso ponto de vista, o campo 
da pedagogia do esporte é aquele que melhor dialoga com a saúde, pois possuem objetivos comuns relacionados à autonomia e emancipação das pessoas.

\subsection{Prática pedagógica em Educação Física e o tema saúde}

Aqui, o relato dos/as profissionais de Educação Física entrevistados/as nos remeteram à uma única categoria de análise: Trabalho em saúde por meio da orientação. Assim, os discursos enveredaram pela figura de orientadores/as dos/as praticantes a partir das mais diversas formas que fossem possíveis. Haja vista, que, nas aulas, o público era diversificado e atendia tanto às crianças, os/as adolescentes, quanto os/as adultos/as e idosos/as. Sem dúvida, que, aqui, a orientação desejada é aquela circunscrita à prática dos exercícios e atividades físicas nos seus diversos segmentos.

Para tanto, há de se considerar neste processo, que, a referida orientação possa e deva assumir diferentes estratégias no que se refere ao seu público-alvo - condição esta, observada, ao longo dos momentos que antecederam e sucederam a realização das entrevistas. Assim, compreendemos, que, seja pelo jogo, pela brincadeira e pelo lazer como conteúdo primordial das práticas voltadas ao grupo das crianças e dos/as adolescentes, este mesmo enredo também se fez presente no que se refere ao contexto dos/as praticantes adultos/as e idosos/as, sem, contudo, desconsiderar o trato para com a repetição e respectiva aprendizagem técnica dos movimentos ao longo de cada uma das modalidades esportivas ministradas pelos/as entrevistados/as.

Tal categoria se faz presente com base nos seguintes recortes:

"[...] nós vamos conversando: aqui, se você [o aluno] praticar, você vai melhorando, vai ampliar sua respiração, mas se você sentir qualquer coisa, você me avisa! A gente vai dando esses alertas, quase que individual mesmo, pois o esporte pode fazer bem e fazer mal" Margarida. "Existem.... Quando como aconteceu aqui logo que eu entrei, quando dei uma palestra para os alunos. [...] Tudo isto [conteúdo saúde] foi sendo passado para os meus alunos, desde 2006; 2007, quando fui assumindo as turmas" - Maria. "No caso deles [alunos], o desafio seria uma maneira, um momento. Vou falar em momentos... Momento de estimulá-los, falando no aspecto biológico, a terem diferentes intensidades daquilo que eles estão fazendo. [...] Indiretamente, a gente meio que é forçado a lidar com questões de saúde, pois esta população tem muitas limitações" - José. "Eu acho.... Que nos momentos das conversas mesmo. Pois numa aula geral igual aqui na sala de musculação, você vai passando, corrigindo o aluno e daí vai passando, assim, no papo, o conceito de saúde. E aí, nesse momento, a gente dá dicas" - João. [...] as pessoas muitas vezes só querem conversar; serem ouvidas, as conversas motivacionais no dia a dia é uma estratégia interessante; porém, fazendo com que ela [a pessoa] entenda e não tenha uma mera reprodução sem questionamentos pertinentes a esta prática; não existe uma transferência direta; tento reforçá-las de forma positiva nas situações que eles mostram maior apropriação" - Rodrigo. "[...] numa perspectiva de promoção e manutenção da saúde, inclusive, falo também da questão do esporte; tento conscientizá-los sobre a importância da prática esportiva em relação à saúde" - Fernanda. 
"[...] eu faço algumas perguntas para os alunos; existe um questionário que eu faço com eles sobre o histórico de vida e sobre a saúde deles de uma forma geral. [...] E claro, eu vou sempre falando com os alunos ao longo das aulas, como disse, vou procurando ter o feedback deles" Joaquim. "[...] na iniciação, esse trabalho é feito de forma geral, muito indiretamente. Não exige algo específico sobre o assunto, mas na realização dos exercícios, reforçamos sobre alimentação, preparação física e falamos dessa melhora da saúde por meio do esporte e que os alunos levam para sua vida cotidiana. Mas como eu disse lá no início, o enfoque do trabalho não é esse! O esporte e sua prática sempre vai "pingar" no tema saúde" - Jorge. No geral esse assunto é tratado por meio de conversas e bate papos de acordo com a demanda. [...] quando o atleta se lesiona, seja em competições ou nos treinos, também conversamos com eles - Daniel.

$\mathrm{Na}$ análise das entrevistas, a proposta de orientação no trabalho em saúde, ganhou força ao perpassar tanto pela concepção ampla, quanto pela concepção estrita no que se refere à ideia da prática esportiva com vista à saúde. A condição de orientador/a no trabalho em saúde se deu em grande parte por meio da afirmação que o esporte cumpra seu papel em relação à saúde respeitando os limites que são apresentados pelos seus praticantes e estabelecendo minimamente uma relação de confiança entre os sujeitos envolvidos nesse universo. Desse modo, infere-se no entendimento que essa relação esteja imbuída pelo caráter educacional do esporte, sobretudo, dada a compreensão da proposta de educação em saúde (CARVALHO, 2001; RABELLO, 2010).

Aqui, percebem-se ferramentas de instrumentalização da orientação e busca pela autonomia e empoderamento como valores expressos e reforçadores do olhar educacional para a relação entre esporte e saúde. Com isso, compreendemos, que, a relação dialógica entre os valores supracitados, constitui forte elo entre educadores/as e educandos/as. Nesse sentido, surge a motivação pessoal no aprimoramento teórico da prática pedagógica, a fim de melhor embasar a atuação dos/as voluntários/as (BRACHT, 2005a, 2005b, 2013; KUNZ, 2016).

A preocupação dos/as voluntários/as com as estratégias empregadas no seu cotidiano, revelou de forma ímpar a característica do trabalho em saúde por meio da orientação. Com isso, o papel dos/as profissionais de Educação Física, se justificou por meio da função de facilitadores/as no processo de saúde. De certo modo, inferindo-se na compreensão, de que, na categoria apresentada, essa condição assuma o status de provocação, compreendendo importante ferramenta no complexo processo de promoção da saúde.

Nesse sentido, os/as alunos/as já vêm preparados/as minimamente. Sobretudo, ao pensar no acesso facilitado às informações relacionadas à saúde como tema, assim, observando-se certa carga de conhecimento acerca da modalidade praticada. Nas conversas classificadas como informais - no transcorrer das aulas, nos diálogos concebidos em meio às instruções acerca do conteúdo trabalhado em cada uma das modalidades esportivas, passam a ser notados, espaços e locais abertos à mediação e orientação para o trabalho em saúde. Ou seja, a orientação em saúde, aqui, ocorre, para além do objetivo específico de cada uma das aulas. No discurso que se faz sobre a prática 
pedagógica com base no caráter educacional da relação entre prática esportiva e saúde, salientamos que o mesmo se traduziu fortemente influenciado pelas questões acerca da promoção e manutenção da saúde.

Ainda, que, indiretamente, a ênfase desse trabalho ocorre e nota-se que para os diversos tipos de público, a informação de algum modo já se encontra enraizada, possibilitando mediante a demanda, o desenvolvimento do papel de mediação, assim, legitimando a realidade profissional dos/as voluntários/as.

\section{Considerações finais}

O binômio esporte-saúde na prática social da Educação Física traduz-se na visão que legitimou e ainda legitima sua importância na sociedade. A perspectiva da prática esportiva como meio de acesso e permanência à saúde como um estado, desprovida de sua devida leitura crítica com vista à apropriação de seus praticantes, reforça a visão utilitarista do processo. Com isso, como possibilidade para uma compreensão qualitativa deste contexto, bem como para se alargar a discussão proposta no presente estudo, consideramos que, na sua instrumentalização, se deve levar em conta a perspectiva ampliada acerca dos múltiplos olhares, ideias, ações e metodologias empregadas no seu cotidiano. Ou seja, o esporte e sua prática, deverão ser compreendidos à luz dos/as praticantes, considerando o fenômeno como um todo, a partir do trato para com a dimensão cultural dos indivíduos. Para tanto, devendo ser elencados no contexto da saúde como possibilidade do trabalho de educação e orientação. Assumindo, assim, uma perspectiva que seja capaz do diálogo com os determinantes sociais em saúde.

Embora o estudo possua suas limitações, já que foi desenvolvido com $10 \%$ dos profissionais de Educação Física lotados numa Secretaria Municipal de Esportes de um município da Baixada Santista, fica nítido que o binômio esportesaúde instrumentaliza grande importância nas estratégias empregadas na diversidade de sua prática pedagógica. Ainda que indiretamente, existe a compreensão sobre prática esportiva e o fomento à saúde, fato que tem como desfecho o/a profissional de Educação Física na figura do/a orientador/a, mediador/a no trabalho em saúde.

\section{REFERÊNCIAS}

ALMEIDA, Ueberson Ribeiro; OLIVEIRA, Victor José Machado de; BRACHT, Valter. Educação Física Escolar e o Trato Didático-Pedagógico com a Saúde: desafios e perspectivas. In: WACHS, Felipe; ALMEIDA, Ueberson Ribeiro; BRANDÃO, Fabiana Fernandes de Freitas. (Orgs.). Educação Física e Saúde Coletiva: cenários, experiências e artefatos culturais. Porto Alegre: Rede UNIDA, 2016, v. 1, p.86-112.

BERGAMO, Luiz Guilherme; SILVA, Cinthia Lopes da. Os significados do Projeto Esporte Cidadão de Indaiatuba-SP para seus frequentadores. Licere. Belo Horizonte, v. 23, n. 4, p. 119-155, 2020. 
BRACHT, Valter. Educação Física e Aprendizagem Social. 2a. Ed. Porto Alegre: Magister, 2005a.

BRACHT, Valter. Sociologia Crítica do Esporte: uma introdução. $3^{a}$. Ed. Ijuí: Unijuí, 2005b.

BRACHT, Valter. Educação Física \& Saúde Coletiva: reflexões pedagógicas. In: FRAGA, Alex Branco; CARVALHO, Yara Maria de; GOMES, Ivan Marcelo (Orgs.). As Práticas Corporais no Campo da Saúde. São Paulo: Hucitec, 2013. p. 178-196.

BRASIL. Conferência Nacional de Saúde, VIII, 1986 Brasília. Relatório Final. Brasília: Ministério da Saúde, 1986. Disponível em:

https://bvsms.saude.gov.br/bvs/publicacoes/8_conferencia_nacional_saude_re latorio_final.pdf. Acesso em: 15 jul. 2017.

BRASIL. MINISTÉRIO DO ESPORTE. Diagnóstico Nacional de Esporte, I, 2015. Brasília: 2015. Disponível em: http://www.esporte.gov.br/diesporte/. Acesso em: 13 jul. 2017.

BRASIL. MINISTÉRIO DO ESPORTE. Diagnóstico Nacional de Esporte, II, 2016. Brasília: Ministério do Esporte, 2016. Disponível em:

http://www.esporte.gov.br/diesporte/. Acesso em: 18 nov. 2018.

CAMPOS, Claudinei José Gomes. Método de Análise de Conteúdo: ferramenta para a análise de dados qualitativos no campo da saúde. Revista Brasileira de Enfermagem, Brasília, v. 57, n. 5, p. 611-614, 2004.

CARVALHO, Yara Maria. Atividade física e Saúde: onde está e quem é o "sujeito" da relação? Revista Brasileira de Ciências do Esporte, Campinas, v. 22, n. 2, p. 9-21, 2001.

CASTELLANI FILHO, Lino. Educação Física no Brasil: a história que não se conta. 19a. Ed. 5a. reimp. Campinas: Papirus, 2015.

COSTA, Filipe Ferreira da; GARCIA, Leandro Martim Totaro; NAHAS, Markus Vinícius. A Educação Física no Brasil em Transição: perspectivas para a promoção da atividade física. Revista Brasileira de Atividade Física e Saúde, Pelotas, v. 17, n. 1, p. 14-21, 2012.

CZERESNIA, Dina. O Conceito de Saúde e a Diferença entre Prevenção e Promoção. In: CZERESNIA, Dina; FREITAS, Carlos Machado de (Orgs.). Promoção da Saúde: conceitos, reflexões tendências. Rio de Janeiro: Editora da Fiocruz, 2003, p.39-53.

DAOLIO, Jocimar. Educação Física e o Conceito de Cultura. Campinas: Autores Associados, 2004. 
DAOLIO, Jocimar. Futebol, Cultura e Sociedade. Campinas: Autores Associados, 2005.

DAOLIO, Jocimar. Da Cultura do Corpo. 12a. Ed. Campinas: Papirus, 2007.

DAOLIO, Jocimar; VELOZO, Emerson. Luís. A técnica esportiva como construção cultural: implicações para a pedagogia do esporte. Pensar a Prática, Goiânia, v. 11, n. 1, p. 9-16, 2008.

DEVIDE, Fabiano Pires. Educação Física, Qualidade de Vida e Saúde: campos de intersecção e reflexões sobre a intervenção. Movimento. Porto Alegre, v.8, n.2, p.77-84, 2002.

FERREIRA, Marcos Santos; CASTIEL, Luís David; CARDOSO, Maria Helena Cabral de Almeida. Atividade Física na Perspectiva da Nova Promoção da Saúde: contradições de um programa institucional. Ciência \& Saúde Coletiva. Rio de Janeiro, v.16, supl.1, p.865-872, 2011.

GALATTI, Larissa Rafaela; PAES, Roberto Rodrigues; SEOANE, Antonio Montero. Pedagogia do Esporte e Obesidade: perspectivas para um estilo de vida saudável com base na adequada iniciação esportiva na infância. Pensar a Prática. Goiânia, v. 15, n. 2, p. 484-499, 2012.

GOMES, Mariana Simões Pimentel; MORATO, Márcio Pereira; DUARTE, Edison; ALMEIDA; José Júlio Gavião de. Ensino das lutas: dos princípios condicionais aos grupos situacionais. Movimento. Porto Alegre, v. 16, n. 2, p. 2017-227, 2010.

KUNZ, Elenor. Transformação Didático-Pedagógica do Esporte. 8a. Ed. Ijuí: Unijuí, 2016.

KUNZ, Elenor. Ministério da Saúde Adverte: viver é prejudicial à saúde. In: BAGRICHEVSKY, M; ESTEVÃO, Adriana; PALMA, Alexandre (Orgs.). A saúde em debate na Educação Física volume 3. Ilhéus: Editus, 2007. p. 173-186.

KNUTH, Alan Goularte; LOCH, Mathias Roberto. "Saúde é o que interessa, o resto não tem pressa?" Um ensaio sobre educação física e saúde na escola. Revista Brasileira de Atividade Física e Saúde. Pelotas, v. 19, n. 4, p. 429-440, 2014.

LOVISOLO, Hugo. Em defesa do modelo JUBESA (juventude, beleza e saúde). In: BAGRICHEVSKY, Marcos; PALMA, Alexandre; ESTEVÃO, Adriana (Orgs.). A Saúde em debate na Educação Física. Vol. 2. Blumenau: Nova Letra, 2006, p. $157-175$. 
LOTTI, Alessandro Demel; OLIVEIRA, Rogério Cruz de. Proposta pedagógica para o ensino da natação a partir do modelo pendular. Pensar a Prática. Goiânia, v. 19, n. 3, p. 665-676, 2016.

MARINHO, Vitor. O Esporte Pode Tudo. São Paulo: Cortez, 2010.

MINAYO, Maria Cecília de Souza. O Desafio do Conhecimento: pesquisa qualitativa em saúde. 14a. Ed. São Paulo: Hucitec, 2014.

OLIVEIRA, Victor José Machado de; MARTINS, Izabella Rodrigues; BRACHT, Valter. Projetos e Práticas para Educação para Saúde na Educação Física Escolar: Possibilidades! Revista de Educação Física da UEM. Maringá, v. 26, n. 2, p. 243-255, 2015.

PALMA, Alexandre. Tensões e possibilidades nas interações entre Educação Física, saúde e sociedade. In: WACHS, Felipe; LARA, Larissa; ATHAYDE, Pedro. (Orgs.). Ciências do Esporte, Educação Física e Produção do Conhecimento em 40 anos do CBCE. v. 11, Natal: Editora da UFRN, 2020. p.15-27.

PAES, Roberto Rodrigues; BALBINO, Hermes Ferreira. A pedagogia do esporte e os jogos coletivos. In: DE ROSE JÚNIOR, Dante. (Org.). Esporte e Atividade Física na Infância e Adolescência: uma abordagem multidisciplinar. 2a. Ed. $1^{a}$. reimp. Porto Alegre: Artmed, 2011. p. 73-83.

PICH, Santiago. Saberes do/sobre o corpo: governamentalidade, biopolítica e o cuidado de si. In: CARVALHO, Yara Maria de; FRAGA, Alex Branco; GOMES, Ivan Marcelo (Orgs.) As práticas corporais no campo da saúde - volume 3. São Paulo: Hucitec Editora, 2016. p.154-171.

SANTOS, Márcio de Souza; FOURAUX, Carolina Gonçalves da Silva; OLIVEIRA, Valéria Marques de. Narrativa de um atleta de bocha paralímpica: ouvindo os que não falam. Mental. Barbacena, v. 11, n. 20, p. 176-205, jun. 2017.

SCAGLIA, Alcides José; REVERDITO, Riller Silva. Pedagogia do Esporte: jogos coletivos de invasão. São Paulo: Phorte, 2009.

SILVA, Douglas Verônico Alves da. Proposta pedagógica para o ensino do futebol em sua relação com a saúde. 2020. 104 f. Dissertação (Mestrado em ciências). Programa Interdisciplinar em Ciências da Saúde, Universidade Federal de São Paulo Campus Baixada Santista, Santos, 2020.

TRIVIÑOS, Augusto Nibaldo Silva. Introdução à Pesquisa em Ciências Sociais: a pesquisa qualitativa em educação. 18a. reimp. São Paulo: Atlas, 2009. 
TUBINO, Manoel José Gomes. O Que é Esporte? 3a. Ed. São Paulo: Brasiliense, 2006.

TUBINO, Manoel José Gomes. Estudos Brasileiros Sobre o Esporte: ênfase no esporte educação. Maringá: Eduem, 2010.

Recebido em: 16 de dezembro de 2020.

Aceito em: 28 de junho de 2021. Publicado em: 15 de dezembro de 2021. 